\title{
A Colorimetric Enzyme-Linked Immunosorbent Assay with CuO Nanoparticles as Signal Labels Based on the Growth of Gold Nanoparticles In Situ
}

\author{
Dehua Deng ${ }^{1,3}$, Yuanqiang Hao ${ }^{2}$, Jiajia Xue ${ }^{3}$, Xiuhua Liu ${ }^{1, *}$, Xinyue $\mathrm{Xu}^{3}$ and Lin Liu ${ }^{2,3, *}$ \\ 1 College of Chemistry and Chemical Engineering, Henan University, Kaifeng 475001, Henan, China; \\ ddh@aynu.edu.cn \\ 2 Henan Key Laboratory of Biomolecular Recognition and Sensing, College of Chemistry and Chemical \\ Engineering, Shangqiu Normal University, Shangqiu 476000, Henan, China; haoyuanqiang@aliyun.com \\ 3 Henan Province of Key Laboratory of New Optoelectronic Functional Materials, Anyang Normal University, \\ Anyang 455000, Henan, China; xjj18239553249@aliyun.com (J.X.); xinyuexu@aliyun.com (X.X.) \\ * Correspondence: liuxiuhua@henu.edu.cn (X.L.); liulin@aynu.edu.cn (L.L.); Tel.: +86-372-330-0925 (L.L.)
}

Received: 20 November 2018; Accepted: 15 December 2018; Published: 20 December 2018

\begin{abstract}
A colorimetric immunoassay has been reported for prostate-specific antigen (PSA) detection with $\mathrm{CuO}$ nanoparticles $(\mathrm{CuO} \mathrm{NPs})$ as signal labels. The method is based on $\mathrm{Cu}^{2+}$-catalyzed oxidation of ascorbic acid (AA) by $\mathrm{O}_{2}$ to depress the formation of colored gold nanoparticles (AuNPs). Specifically, $\mathrm{HAuCl}_{4}$ can be reduced by AA to produce AuNPs in situ. In the presence of target, $\mathrm{CuO}$ NPs-labeled antibodies were captured via the sandwich-type immunoreaction. After dissolving $\mathrm{CuO}$ nanoparticles with acid, the released $\mathrm{Cu}^{2+}$ catalyzed the oxidation of $\mathrm{AA}$ by $\mathrm{O}_{2}$, thus depressing the generation of AuNPs. To demonstrate the accuracy of the colorimetric assay, the released $\mathrm{Cu}^{2+}$ was further determined by a fluorescence probe. The colorimetric immunoassay shows a linear relationship for PSA detection in the range of $0.1 \sim 10 \mathrm{ng} / \mathrm{mL}$. The detection limit of $0.05 \mathrm{ng} / \mathrm{mL}$ is comparable to that obtained by other CuO NPs-based methods. The high throughput, simplicity, and sensitivity of the proposed colorimetric immunoassay exhibited good applicability for assays of serum samples.
\end{abstract}

Keywords: colorimetric immunoassay; $\mathrm{CuO}$ nanoparticles; gold nanoparticles; ascorbic acid; fluorescence immunoassay

\section{Introduction}

Biosensors have been developed for detection of various analytes in the fields of clinical diagnostics, food industry, pharmaceutical chemistry, and environmental science. As to the recognition elements, antibodies are the most commonly used biorecognition molecules in construction of biosensors although many efforts have being made to replace antibodies with alternative recognition molecules [1-3]. Thus, immunoassays are still the most widespread analytical methods for the selective and sensitive detection of targets. For example, enzyme-linked immunosorbent assay (ELISA) represents the most popular technique of immunoassays in many fields. However, there still remain some disadvantages about classical ELISA assays, including the complicated and time-consuming implementation procedure, the use of enzyme-labeled, fluorescent or chemiluminescent antibodies, and the bulky measurement instrument. Therefore, numerous attempts have being made to improve the conventional immunosensing concepts [4].

To replace the classic enzyme labels, nanomaterials as signal reporters have attracted tremendous attention in the development of immunosensors, which include metal or metallic oxides, metal-organic frameworks (MOFs), luminescent nanocrystals, etc. [5-8] After being specifically captured on the 
sensing interface, the nanolabels can produce a detectable signal directly or be converted into the respective metal ions that can be determined by electric or optical techniques. Since each nanolabel contains large numbers of detectable atoms, the latter is more promising for the construction of highly sensitive immunosensors [9]. For example, $\mathrm{CuO}$ nanoparticles have been recently employed for the signal probes of immunosensors because of their advantages of low cost and good stability. After dissolving $\mathrm{CuO}$ nanoparticles with acid, the released $\mathrm{Cu}^{2+}$ ions can be determined by electric or optical techniques [10-16]. Among them, the fluorescence assays show high sensitivity. The released $\mathrm{Cu}^{2+}$ ions can be directly quantified with fluorescent dyes, quantum dots and nanomaterials or be indirectly determined based on the copper-catalyzed generation of fluorescent molecules [10-14]. In contrast to fluorescence assays, colorimetric assays exhibit high simplicity and require minimum instrumental investment despite their comparatively low sensitivity [17-19]. For example, based on the $\mathrm{Cu}^{+}$-catalyzed click chemistry, Qu et al. reported a colorimetric immunoassay using azide- and alkyne-modified gold nanoparticles (AuNPs) as the probes [18]. In view of the peroxidase-like catalytic activity of $\mathrm{Cu}^{2+}$ to catalyze $\mathrm{H}_{2} \mathrm{O}_{2}$-mediated oxidation of 3, 3', 5, 5'-tetramethylbenzidine (TMB), Zheng et al. developed an immunosensor by monitoring the generation of colored oxidation product of TMB [19]. The signal has been amplified by the $\mathrm{Cu}^{2+} / \mathrm{Cu}^{+}$-catalyzed reaction. However, in the AuNPs-based immunoassay, the AuNPs need to be prepared and modified with double recognition elements. For the $\mathrm{Cu}^{2+}$-catalyzed oxidation of TMB system, high concentration of $\mathrm{Cu}^{2+}$ is required to produce colored products. Therefore, there still remains room to develop simple and sensitive colorimetric immunosensors with $\mathrm{CuO}$ NPs labels.

Free $\mathrm{Cu}^{2+}$ ions can catalyze the oxidation of ascorbic acid (AA) by $\mathrm{O}_{2} ; \mathrm{AA}$ as a reducing regent can reduce $\mathrm{HAuCl}_{4}$ into AuNPs [20,21]. Based on these facts, we have developed a protease biosensor in that peptide with an amino terminal copper and nickel-binding (ATCUN) motif can inhibit the $\mathrm{Cu}^{2+}$-catalytic reaction by complexation with $\mathrm{Cu}^{2+}$ to allow for the AA-regulated growth of AuNPs in situ [22]. In view of the high extinction coefficient of AuNPs, herein, we developed an immunosensor by monitoring the generation of AuNPs, which is mediated by the $\mathrm{Cu}^{2+}$-catalytic oxidation of AA. Moreover, ATCUN peptide binds to $\mathrm{Cu}^{2+}$ with high affinity $\left(10^{-16} \mathrm{M}\right)$, and $\mathrm{Cu}^{2+}$ can cause the fluorescent quenching of fluorophore by electron or energy transfer when binding to the recognition unit [23-25]. The released $\mathrm{Cu}^{2+}$ ions from the $\mathrm{CuO}$ NPs labels were further quantified by a fluorescently-labeled ATCUN peptide probe. The analytical performances of the colorimetric and fluorescent methods were compared with those achieved by other $\mathrm{CuO}$ NPs-based immunosensors.

\section{Materials and Methods}

\subsection{Chemicals and Materials}

Prostate-specific antigen (PSA) antigen, first and second PSA antibodies (Ab1 and Ab2) and ELISA kits were ordered from Linc-Bio Science Co. LTD (Shanghai, China). CuO NPs were obtained from Nanjing XFNANO Materials Tech Co., Ltd. (Nanjing, China). Bovine serum albumin (BSA), immunoglobin $\mathrm{G}(\mathrm{IgG})$, albumin and hemoglobin were obtained from Sigma-Aldrich (Shanghai, China). Fluorescently-labeled peptide SGHK-Dns was ordered from ChinaPeptides Co., Ltd. (Shanghai, China). Serum sample from one 36-year-old donor was provided by the health center of Anyang Normal University (Anyang, China). All the other chemicals were purchased from Aladdin Reagent Company (Shanghai, China). They are of analytical grade and used as received without additional purification. The solutions were prepared freshly with deionized water treated using a Millipore Milli-Qwater.

\subsection{Labeling of Antibody with $\mathrm{CuO} N \mathrm{NPS}_{\mathrm{s}}$}

The procedure for labeling of antibody with $\mathrm{CuO}$ NPs follows that of the previously reported methods with slight modification [14,18]. Briefly, $0.5 \mathrm{mg}$ of $\mathrm{CuO}$ NPs were dispersed in $0.5 \mathrm{~mL}$ of $10 \mathrm{mM}$ phosphate buffer saline (PBS, pH 7.4) by 10 -min sonication. Then, $10 \mu \mathrm{L}$ of the Ab2 $(1 \mathrm{mg} / \mathrm{mL})$ was added to the $\mathrm{CuO}$ NPs solution. The suspension was shaken slightly for $120 \mathrm{~min}$, followed by 
centrifugation at $5000 \mathrm{rpm}$ for $5 \mathrm{~min}$. The precipitate was then washed three times with PBS to remove unlabeled Ab2. The resulting $\mathrm{CuO}$ NPs-antibody conjugates (Ab2-CuO NPs) were dispersed with $0.2 \mathrm{~mL}$ of PBS containing $0.1 \%$ BSA and shaken slightly for $30 \mathrm{~min}$. The mixture was then centrifuged and washed to remove free BSA. Finally, the obtained $\mathrm{Ab}_{2}-\mathrm{CuO}$ NPs were re-dispersed in $1 \mathrm{~mL}$ of PBS and stored at $4{ }^{\circ} \mathrm{C}$ for use.

\subsection{Procedure for PSA Detection}

$40 \mu \mathrm{L}$ of PBS or serum sample containing PSA was added to the ELISA plate and incubated at $37^{\circ} \mathrm{C}$ for $1 \mathrm{~h}$. After washing the plate with the diluted cleaning solution five times, $40 \mu \mathrm{L}$ of the prepared Ab2-CuO NPs suspension was added and incubated for $1 \mathrm{~h}$ again. This step was followed by washing the plate with deionized water five times to remove unbound Ab2-CuO NPs. Next, $100 \mu \mathrm{L}$ of $10 \mathrm{mM} \mathrm{HCl}$ was added to the plate to shake for $5 \mathrm{~min}$. To prevent the generated AuNPs from adhering on the plate, the colorimetric assay was conducted on a centrifuge tube. Briefly, $100 \mu \mathrm{L}$ of PBS (20 mM, $\mathrm{pH}$ 7.2) was first added to the above plate to bring the final $\mathrm{pH}$ to about 7.0. Then, $50 \mu \mathrm{L}$ of $0.75 \mathrm{mM}$ AA stock solution was added to the plate for 30-min incubation. Next, $200 \mu \mathrm{L}$ of the solution was taken out and mixed with $25 \mu \mathrm{L}$ of $5 \mathrm{mM}$ hexadecyltrimethylammonium chloride (CTAC) solution, and then $25 \mu \mathrm{L}$ of $2 \mathrm{mM} \mathrm{HAuCl}_{4}$ was added to the mixed solution in batches. The color change was observed by the naked eye and the absorption spectra were collected on a Cary $60 \mathrm{UV}$-Vis spectrophotometer.

For the fluorescent assay of the released $\mathrm{Cu}^{2+}, 100 \mu \mathrm{L}$ of PBS containing $4 \mu \mathrm{M}$ probe was added to the plate following the addition of $\mathrm{HCl}$. Then, the solution was taken out and measured on the FLS980 Steady State Fluorescence and Phosphorescence Lifetime Spectrometer with an excitation wavelength of $340 \mathrm{~nm}$.

\subsection{Assay of PSA with ELISA Kits}

$40 \mu \mathrm{L}$ of standard PSA sample or serum sample was added to the ELISA plate and incubated at $37^{\circ} \mathrm{C}$ for $1 \mathrm{~h}$. After washing the plate with the diluted cleaning solution five times, $100 \mu \mathrm{L}$ of the HRP-labeled antibody (HRP-Ab) solution was added and incubated for $1 \mathrm{~h}$ again. Then, the plate was washed with the diluted cleaning solution five times to remove unbound HRP-Ab. Next, $100 \mu \mathrm{L}$ of the mixed solution of TMB and $\mathrm{H}_{2} \mathrm{O}_{2}$ was added to the plate to incubated for $15 \mathrm{~min}$, which is followed by the addition of $50 \mu \mathrm{L}$ of stopping solution. Finally, the signal intensity at $450 \mathrm{~nm}$ was recorded with an ELISA microplate reader.

\section{Results and Discussion}

\subsection{Detection Principle}

The detection principle of our immunosensor with antibodies-modified CuO NPs as labels is presented in Figure 1, which follows the classical sandwich structure. PSA, a biomarker of prostate diseases such as prostate cancer, prostatitis and benign prostatic hyperplasia, is tested as the model analyte. The immunoassay was carried out on a solid/liquid interface of 96-well plate. The secondary anti-PSA was labeled with CuO NPs (Ab2-CuO NPs). In the detection step, the captured CuO NPs are first dissolved by $\mathrm{HCl}$ to produce a lot of $\mathrm{Cu}^{2+}$ ions (Figure 1a). AA can be directly oxidized into dehydroascorbic acid (DA) by $\mathrm{Cu}^{2+}$; then, the resulting $\mathrm{Cu}^{+}$is rapidly oxidized into $\mathrm{Cu}^{2+}$ by $\mathrm{O}_{2}$. This $\mathrm{Cu}^{2+}$-initiated redox cycling promotes the consumption of AA and thus depresses the AA-regulated generation of AuNPs. Because the color change of the generated AuNPs can be readily observed with naked eyes, no instrument is required for the readout. The amount of the released $\mathrm{Cu}^{2+}$ or the captured CuO NPs is dependent upon the target concentration. Thus, the solution color and absorbance signal change induced by the $\mathrm{Cu}^{2+}$-catalyzed reaction can be used for the quantitative immunoassays. To demonstrate the accuracy and sensitivity of the colorimetric assay, the released $\mathrm{Cu}^{2+}$ was simultaneously quantified with a fluorescence probe. Because $\mathrm{Cu}^{2+}$ exhibits both high binding affinity to ATCUN peptide and high quenching ability towards the Dns group, an ATCUN peptide of 
SGHK labeled with a fluorophore Dns on the side chain of lysine $(\mathrm{K})$ residue was used as the $\mathrm{Cu}^{2+}$ sensing probe (denoted as SGHK-Dns) (Figure 1b). After formation of the $\mathrm{Cu}^{2+}$-peptide complex, the fluorescence of SGHK-Dns would be quenched.
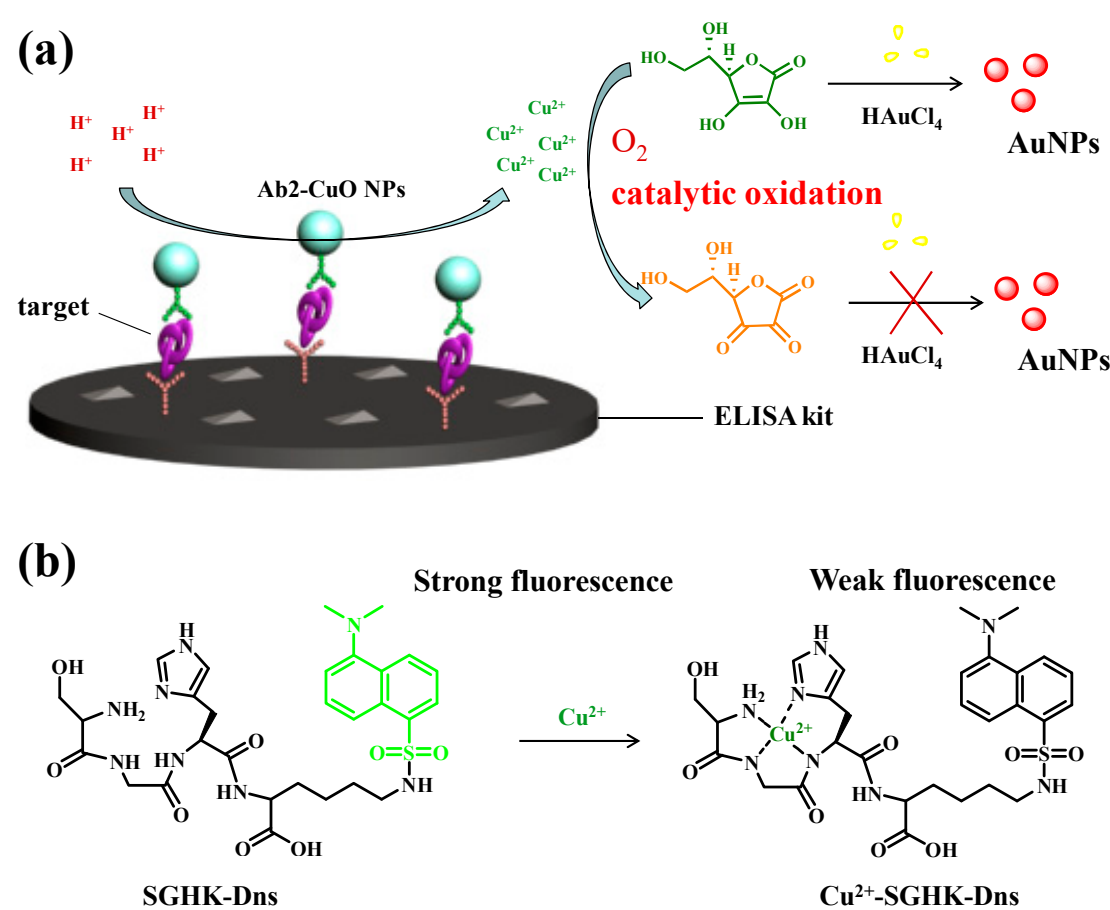

Figure 1. (a) Schematic representation of the immunosensor with $\mathrm{CuO}$ nanoparticle (CuO NP) labels based on the $\mathrm{Cu}^{2+}$-catalyzed ascorbic acid (AA) oxidation and in situ growth of AuNPs; (b) Fluorescence detection of the released $\mathrm{Cu}^{2+}$ with the probe of SGHK-Dns.

\subsection{Optimization of Experimental Conditions}

AA concentration and solution $\mathrm{pH}$ play decisive roles in the generation of AuNPs. Our early investigations have demonstrated that $\mathrm{HAuCl}_{4}$ can be reduced to AuNPs by AA at neutral $\mathrm{pH}$ and $\mathrm{Cu}^{2+}$ at micromolar concentration can catalyze the exhaustion of $200 \mu \mathrm{M}$ AA within $10 \mathrm{~min}$ [22]. In the present work, the optimized experimental conditions for AuNPs generation followed those of our early work. To demonstrate the binding stoichiometry and fluorescence quenching efficiency of $\mathrm{Cu}^{2+}$ to the peptide probe, the fluorescence spectra of SGHK-Dns in the presence of various concentrations of $\mathrm{Cu}^{2+}$ were collected. As shown in Figure 2a, the fluorescence signal of the peptide decreased gradually with the increase of $\mathrm{Cu}^{2+}$ concentration. The value reached to the minimum in the presence of 1 equiv of $\mathrm{Cu}^{2+}$, which is indicative of a 1:1 binding ratio (Figure 2b). The result also demonstrated that labeling of Dns group on the side chain of lysine residue did not decrease the binding affinity of ATCUN peptide with $\mathrm{Cu}^{2+}$. Moreover, the quenching efficiency was calculated to be $84.8 \%$ with the formula $\left(1-\mathrm{F}^{\prime} / \mathrm{F}^{0}\right) \times 100 \%$, where $\mathrm{F}^{\prime}$ and $\mathrm{F}^{0}$ represent the fluorescence intensity of the probe at $552 \mathrm{~nm}$ with and without addition of $\mathrm{Cu}^{2+}$, respectively. The high quenching efficiency can be attributed the strong interaction and high quenching ability of $\mathrm{Cu}^{2+}$ to the fluorescently-labeled peptide. Thus, the designed peptide probe can be used for the sensitive detection of $\mathrm{Cu}^{2+}$. 
(a)

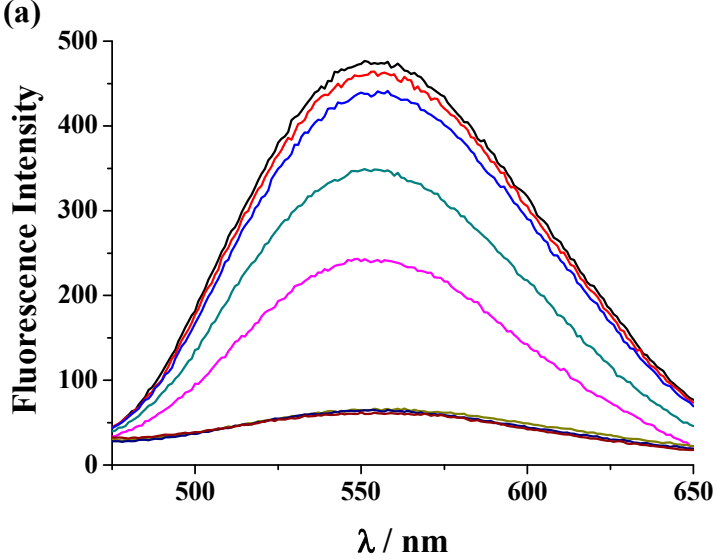

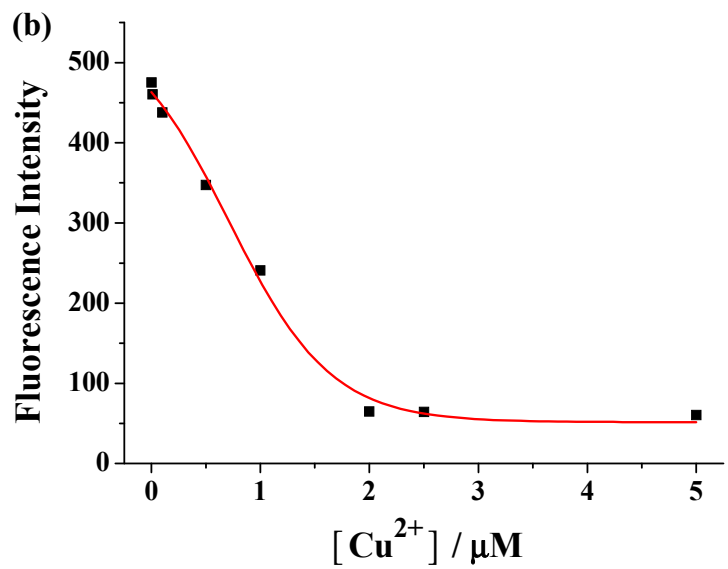

Figure 2. The emission spectra (a) and fluorescence intensity (b) at $552 \mathrm{~nm}$ of $2 \mu \mathrm{M}$ SGHK-Dns in the presence of different concentrations of $\mathrm{Cu}^{2+}$ (from top to bottom: 0, 0.01, 0.1, 0.5, 1, 2, 2.5 and $5 \mu \mathrm{M}$ ).

\subsection{Feasibility}

The feasibility of our strategy was investigated by monitoring the change in color and absorption spectra of the detection solutions at various conditions. As shown in Figure 3a, without Ab2-CuO NPs (curve/tube 1) or PSA (curve/tube 2) incubation step, the solution kept red color and the absorbance intensity at $530 \mathrm{~nm}\left(\mathrm{~A}_{530}\right)$ is high. The absorption peak can be ascribed to the surface plasmon resonance of the generated AuNPs. This result indicated that AA was not oxidized and more AuNPs were generated in the absence of Ab2-CuO NPs or PSA. However, in the PSA detection system, the solution was colourless and the absorbance intensity was greatly decreased, indicating that no or less AuNPs were generated (curve/tube 3). This result indicated that the change of solution color and absorbance intensity is dependent upon PSA capture and the specific antibody-antigen interaction. To further prove that the signal change of the colorimetric assay is caused by the released $\mathrm{Cu}^{2+}$ ions from $\mathrm{Ab} 2-\mathrm{CuO}$ NPs, fluorescence assays with SGHK-Dns as the $\mathrm{Cu}^{2+}$ detection probe were carried out. As shown in Figure $3 b$, the fluorescence signal in the PSA detection system is significantly lower than that in the case without PSA or Ab2-CuO NPs capture. The result is consistent with that achieved by the colorimetric assay. Thus, the proposed method based on the target-induced $\mathrm{Cu}^{2+}$ concentration change can be used for development of colorimetric or fluorescence immunosensors.
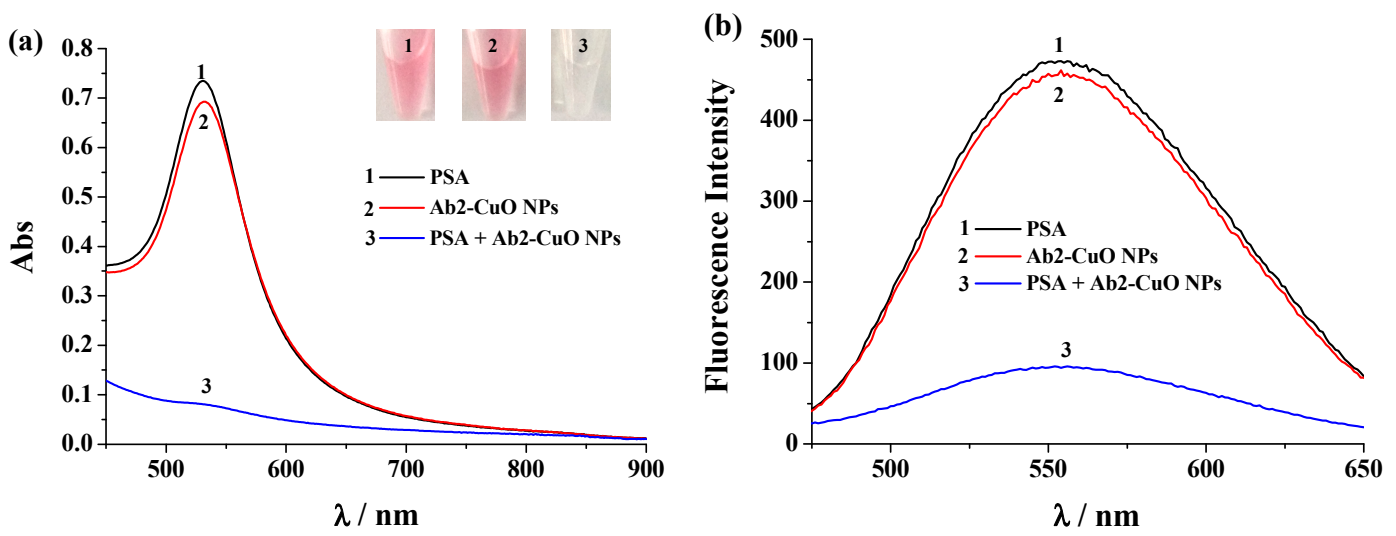

Figure 3. The UV-Vis absorption spectra and photographic images (the inset) (a) and emission spectra (b) for different detection systems. Curve or tube 1, prostate-specific antigen (PSA); curve 2 or tube 2, Ab2-CuO NPs, PSA; curve 3 or tube 3, PSA + Ab2-CuO NPs. The final concentration of PSA was $50 \mathrm{ng} / \mathrm{mL}$. 


\subsection{Sensitivity}

The sensitivity of the immunosensor was investigated by monitoring the color and signal change of the detection system in the presence of different concentrations of PSA. As shown in Figure 4, increasing PSA concentration resulted in the color change from red to colourless and the gradual decrease in the absorbance intensity at $530 \mathrm{~nm}$. The $A_{530}$ value decreased linearly with increasing PSA concentration from 0.1 to $10 \mathrm{ng} / \mathrm{mL}$. The linear equation is $\mathrm{A}_{530}=0.667-0.053$ [PSA] $(\mathrm{ng} / \mathrm{mL})$. The detection limit of this method was estimated to be $0.05 \mathrm{ng} / \mathrm{mL}$ by determining the smallest concentration of PSA at which the signal is clearly distinguishable from the background. The reproducibility of this method was evaluated by analyzing three freshly prepared PSA samples at the same concentration. The relative standard deviations (RSDs, shown as the error bars in Figure $4 \mathrm{~b}$ ) for assays of the parallel prepared samples are all less than $10.2 \%$, suggesting acceptable reproducibility of the proposed immunosensor. To demonstrate the accuracy of the colorimetric assay, PSA concentration was also determined by measurement of the released $\mathrm{Cu}^{2+}$ with the fluorescence probe. As shown in Figure 5, the fluorescence intensity decreases linearly with the increase of PSA concentration in the range of 0.1 to $10 \mathrm{ng} / \mathrm{mL}$ with a calibration equation of $\mathrm{F}=422.5-22.3[\mathrm{PSA}](\mathrm{ng} / \mathrm{mL})$. The detection limit of the fluorescent method was about $0.1 \mathrm{ng} / \mathrm{mL}$. Interestingly, the colorimetric method exhibits a comparable sensitivity with that of the fluorescent assay. Moreover, the detection limit of the proposed immunosensor is comparable to or even lower than that achieved by other CuO-based immunosensors (Table 1). The high sensitivity of the colorimetric immunoassay can be attributed to the high catalytic activity of $\mathrm{Cu}^{2+}$ to AA oxidation, the high extinction coefficient of AuNPs, and the signal amplification of $\mathrm{CuO}$ NPs. For the fluorescent immunoassay, the high sensitivity results from the high binding affinity and quenching ability of $\mathrm{Cu}^{2+}$ to the peptide probe. We believe that the sensitivity may be improved by using more sensitive ELISA plate.
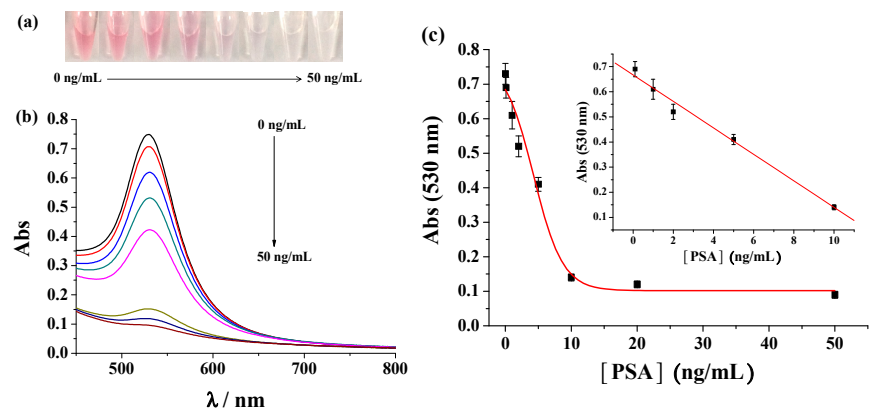

Figure 4. The photographic images (a) and UV-Vis absorption spectra (b) for assays of different concentrations of PSA $(0,0.1,1,2,5,10,20$ and $50 \mathrm{ng} / \mathrm{mL})$.
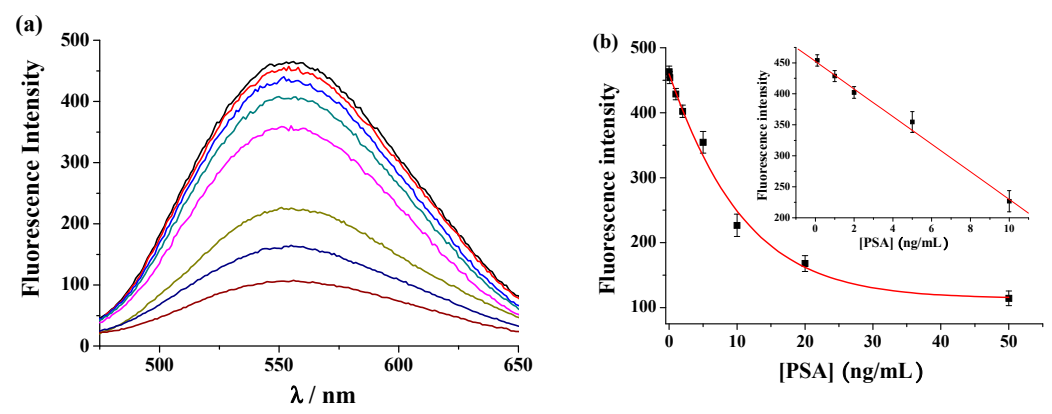

Figure 5. The emission spectra (a) and fluorescence intensity (b) for assays of different concentrations of PSA (from top to bottom: 0, 0.1, 1, 2, 5, 10, 20 and $50 \mathrm{ng} / \mathrm{mL}$ ). 
Table 1. Comparison of analytical performances of various CuO NPs-based biosensors.

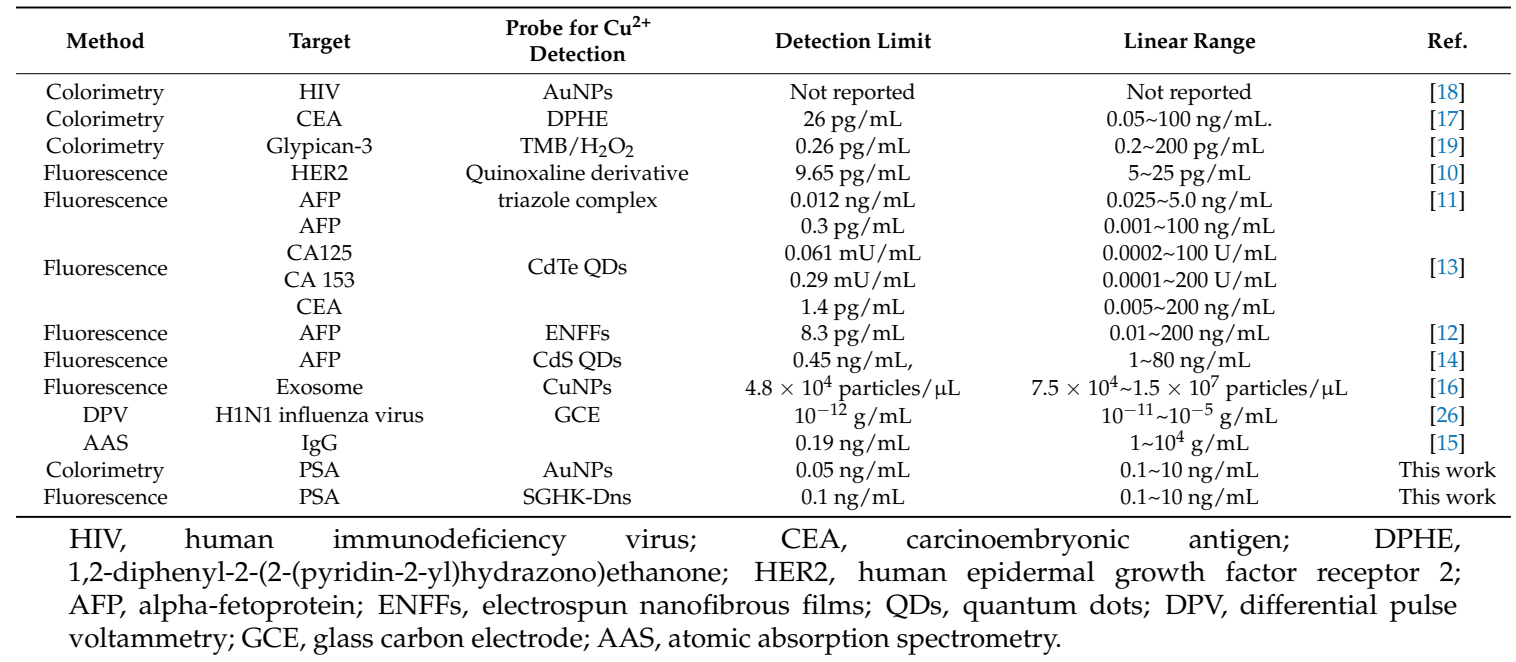

\subsection{Selectivity}

Since the colorimetric assay shows high sensitivity and does not require advanced instrument for signal readout, the selectivity for PSA detection was investigated by the colorimetric method. As shown in Figure 6, for the tested proteins including PSA, BSA, IgG, albumin and hemoglobin, only PSA system resulted in the color change and significant decrease in the absorbance intensity. No significant difference in the color change and absorbance intensity was observed for the non-specific proteins even at the 10-fold higher concentration. The high selectivity can be attributed to the high specificity of antibody with target protein and the low nonspecific adsorption of Ab2-CuO NPs on the ELISA microwells.

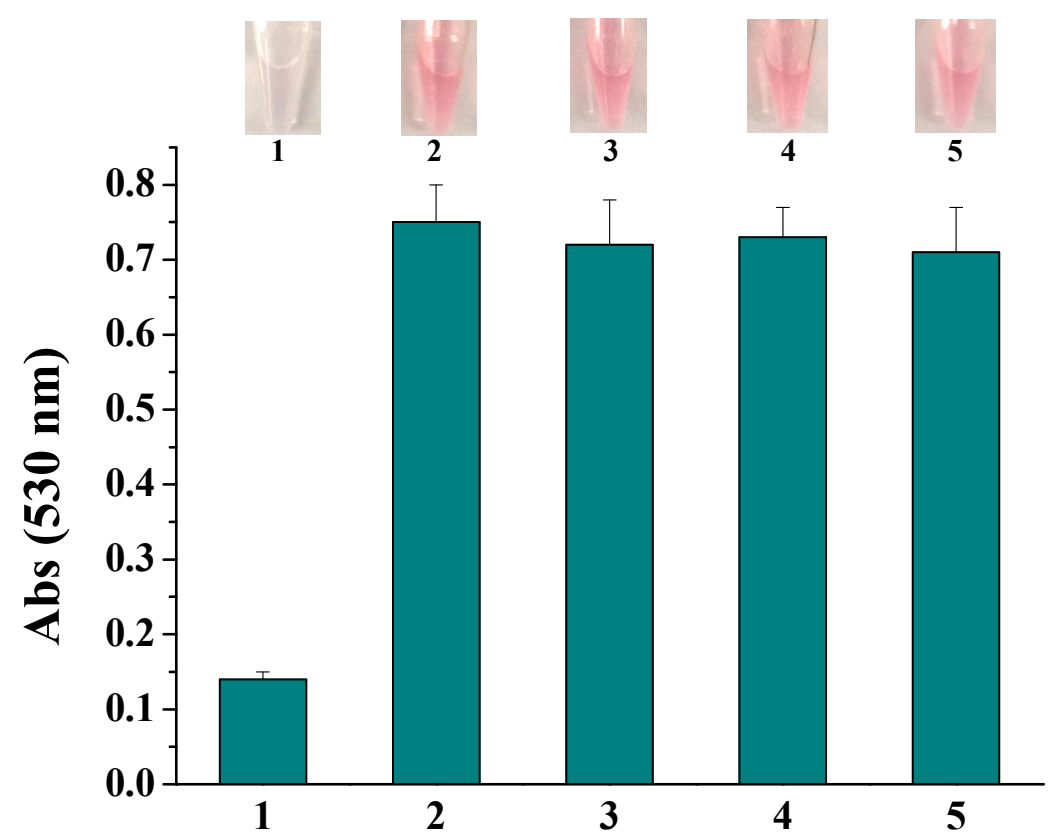

Figure 6. The photographic images and absorption intensity for assays of various proteins (1, PSA; 2, BSA; 3, IgG; 4, albumin; 5, hemoglobin). The final concentration of PSA was $10 \mathrm{ng} / \mathrm{mL}$ and that of other proteins is $100 \mathrm{ng} / \mathrm{mL}$. 


\subsection{Evaluation of Serum Samples}

The detection limit of our colorimetric method is lower than the normal value $(<4 \mathrm{ng} / \mathrm{mL})$ of PSA released by a healthy prostate. Therefore, the method is promising to determine PSA in a biological sample. To demonstrate the amenability of our method for clinical application, a serum sample was tested (Figure 7). As a result, the solution color of the detection system remained red and the absorbance intensity was slight lower than that of the background value. The initiated PSA concentration in the serum was found to be $1.86 \pm 0.12 \mathrm{ng} / \mathrm{mL}$ according to the above established standard curve. The value is lower than $4 \mathrm{ng} / \mathrm{mL}$, demonstrating that the donor is healthy. To prove the accuracy of this assay, standard PSA samples at three given concentrations $(2,4$ and $8 \mathrm{ng} / \mathrm{mL})$ were added to the serum sample and then analyzed with the colorimetric method. It can be observed that addition of PSA to the sample made the red of detection solution become lighter, which is accompanied by the decrease in the absorbance intensity. The final PSA contents found in the sample are close to the total concentrations of the initiated and spiked PSA. Actually, we found that the sensor response after spiking of $0.1 \mathrm{ng} / \mathrm{mL}$ PSA to the serum is clearly distinguishable from that without addition of PSA, which is indicative of high sensitivity of the method for serum sample assay. To ascertain the correctness of the result, the PSA concentrations were further determined with a commercial ELISA kit. No detectable PSA was found in the serum sample with the ELISA kit, demonstrating that the kit is less sensitive for PSA detection. In the PSA-spiked serum samples, the found PSA contents are close to those achieved by the colorimetric method (Table 2). This result indicated that the presented colorimetric immunosensor is applicable for PSA detection in biological samples and can offer a useful means for clinical investigations.

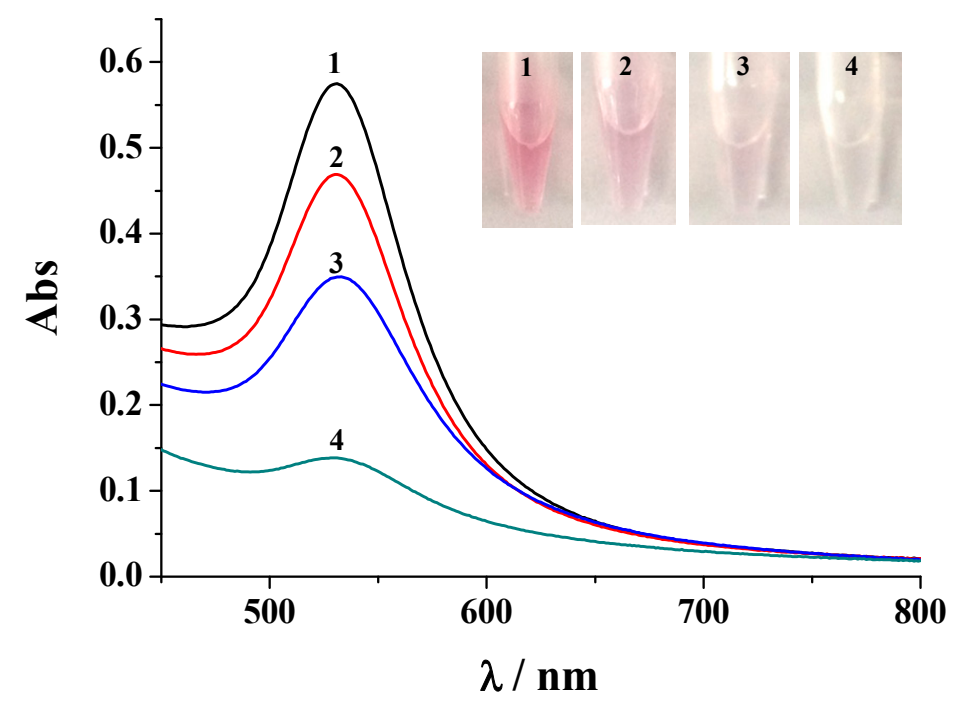

Figure 7. The UV-Vis absorption spectra and the photographic images (the inset) for assays of PSA in serum samples. Curves/tubes 1 4 correspond to the serum samples spiked with $0,2,4$, and $8 \mathrm{ng} / \mathrm{mL}$ PSA, respectively.

Table 2. Assays of PSA in serum samples.

\begin{tabular}{cccc}
\hline Sample No. & Added $(\mathbf{n g} / \mathrm{mL})$ & Found $(\mathbf{n g} / \mathrm{mL})$ & ELISA $(\mathbf{n g} / \mathrm{mL})$ \\
\hline 1 & 0 & $1.86 \pm 0.12$ & undetectable \\
2 & 2 & $3.74 \pm 0.23$ & $4.14 \pm 0.21$ \\
3 & 4 & $5.66 \pm 0.42$ & $5.72 \pm 0.52$ \\
4 & 8 & $9.78 \pm 0.74$ & $10.46 \pm 0.83$ \\
\hline
\end{tabular}




\section{Conclusions}

A colorimetric immunassay method with $\mathrm{CuO}$ NPs as the signal labels was reported for the sensitive detection of PSA. The high sensitivity results from the large number of $\mathrm{Cu}^{2+}$ released from the $\mathrm{CuO}$ NPs, the high catalytic activity of $\mathrm{Cu}^{2+}$ to $\mathrm{AA}$ oxidation, and the high extinction coefficient of AuNPs. Moreover, the non-enzymatic colorimetric immunosensor has low cost and satisfactory results for assays of PSA in serum samples. In contrast to the AuNPs aggregation-based colorimetric immunassays with $\mathrm{CuO}$ NPs labels [18], our method does not require the preparation of double-modified AuNPs, thus reducing the operational complexity and detection cost. Considering the outstanding advantages and excellent performances of the method, we believe that the CuO NPs-based immunoassays may have wide-ranging applications in the clinical diagnosis.

Author Contributions: Conceptualization, D.D., Q.H. and L.L.; methodology, D.D. and Q.H.; investigation, D.D., J.X. and X.X.; data curation, D.D., Q.H. and J.X.; writing-original draft preparation, D.D.; writing-review and editing, X.L. and L.L.; project administration, X.L.; funding acquisition, Q.H. and L.L.

Funding: This research was funded by the National Natural Science Foundation of China (21804085) and the fund project for Young Scholar sponsored by Henan province (2016GGJS-122).

Conflicts of Interest: The authors declare no conflict of interest.

\section{References}

1. Farka, Z.; Juřík, T.; Kovář, D.; Trnková, L.; Skládal, P. Nanoparticle-based immunochemical biosensors and assays: Recent advances and challenges. Chem. Rev. 2017, 117, 9973-10042. [CrossRef] [PubMed]

2. Patris, S.; Vandeput, M.; Kauffmann, J.-M. Antibodies as target for affinity biosensors. TrAC-Trend. Anal. Chem. 2016, 79, 239-246. [CrossRef]

3. Li, Z.Y.; Chen, G.Y. Current conjugation methods for immunosensors. Nanomaterials 2018, 8, 278. [CrossRef]

4. Zheng, W.; Jiang, X. Integration of nanomaterials for colorimetric immunoassays with improved performance: A functional perspective. Analyst 2016, 141, 1196-1208. [CrossRef]

5. Rick, J.; Tsai, M.-C.; Hwang, B.J. Biosensors incorporating bimetallic nanoparticles. Nanomaterials 2016, 6, 5. [CrossRef] [PubMed]

6. Zhang, S.; Geryak, R.; Geldmeier, J.; Kim, S.; Tsukruk, V.V. Synthesis, assembly, and applications of hybrid nanostructures for biosensing. Chem. Rev. 2017, 17, 12942-13038. [CrossRef]

7. Fenzl, C.; Hirsch, T.; Baeumner, A.J. Nanomaterials as versatile tools for signal amplification in (bio)analytical applications. TrAC-Trend. Anal. Chem. 2016, 79, 306-316. [CrossRef]

8. Saha, K.; Agasti, S.S.; Kim, C.; Li, X.; Rotello, V.M. Gold Nanoparticles in Chemical and Biological Sensing. Chem. Rev. 2012, 112, 2739-2779. [CrossRef]

9. Kokkinos, C.; Economou, A. Emerging trends in biosensing using stripping voltammetric detection of metal-containing nanolabels-A review. Anal. Chim. Acta 2017, 961, 12-32. [CrossRef]

10. Tian, S.; Zeng, K.; Yang, A.; Wang, Q.; Yang, M. A copper based enzyme-free fluorescence ELISA for HER2 detection. J. Immunol. Method. 2017, 451, 78-82. [CrossRef]

11. Xie, Q.; Weng, X.; Lu, L.; Lin, Z.; Xu, X.; Fu, C. A sensitive fluorescent sensor for quantification of alpha-fetoprotein based on immunosorbent assay and click chemistry. Biosens. Bioelectron. 2016, 77, 46-50. [CrossRef] [PubMed]

12. Yang, T.; Li, C.M.; He, J.H.; Chen, B.; Li, Y.F.; Huang, C.Z. Ratiometrically fluorescent electrospun nanofibrous film as a $\mathrm{Cu}^{2+}$-mediated solid-phase immunoassay platform for biomarkers. Anal. Chem. 2018, 90, 9966-9974. [CrossRef] [PubMed]

13. Ge, S.; Ge, L.; Yan, M.; Song, X.; Yu, J.; Liu, S. A disposable immunosensor device for point-of-care test of tumor marker based on copper-mediated amplification. Biosens. Bioelectron. 2013, 43, 425-431. [CrossRef] [PubMed]

14. Wang, Y.-W.; Chen, L.; Liang, M.; Xu, H.; Tang, S.; Yang, H.-H.; Song, H. Sensitive fluorescence immunoassay of alpha-fetoprotein throughcopper ions modulated growth of quantum dots in-situ. Sensor. Actuator B Chem. 2017, 247, 408-413. [CrossRef]

15. Xu, Y.; Gao, Y.; Zhao, X.; Xu, X.; Zhou, W.; Liu, Y.; Li, C.; Liu, R. A sensitive atomic absorption spectrometric metalloimmunoassay with copper nanoparticles labeling. Microchem. J. 2016, 126, 1-6. [CrossRef] 
16. He, F.; Wang, J.; Yin, B.-C.; Ye, B.-C. Quantification of exosome based on a copper-mediated signal amplification strategy. Anal. Chem. 2018, 90, 8072-8079. [CrossRef] [PubMed]

17. Li, B.; Lai, G.; Zhang, H.; Hu, S.; Yu, A. Copper chromogenic reaction based colorimetric immunoassay for rapid and sensitive detection of a tumor biomarker. Anal. Chim. Acta 2017, 963, 106-111. [CrossRef] [PubMed]

18. Qu, W.; Liu, Y.; Liu, D.; Wang, Z.; Jiang, X. Copper-Mediated Amplification Allows Readout of Immunoassays by the Naked Eye. Angew. Chem. Int. Ed. 2011, 50, 3442-3445. [CrossRef] [PubMed]

19. Zheng, A.; Zhang, X.; Gao, J.; Liu, X.; Liu, J. Peroxidase-like catalytic activity of copper ions and its application for highly sensitive detection of glypican-3. Anal. Chim. Acta 2016, 941, 87-93. [CrossRef] [PubMed]

20. Dekker, A.O.; Dickinson, R.G. Oxidation of ascorbic acid by oxygen with cupric ion as catalyst. J. Am. Chem. Soc. 1941, 63, 3549. [CrossRef]

21. Rastogi, L.; Dash, K.; Ballalb, A. Selective colorimetric/visual detection of $\mathrm{Al}^{3+}$ in ground water usingascorbic acid capped gold nanoparticles. Sensor. Actuator B Chem. 2017, 248, 124-132. [CrossRef]

22. Liu, L.; Deng, D.; Wang, Y.; Song, K.; Shang, Z.; Wang, Q.; Xia, N.; Zhang, B. A colorimetric strategy for assay of protease activity based on gold nanoparticle growth controlled by ascorbic acid and $\mathrm{Cu}(\mathrm{II})$-coordinated peptide. Sensor. Actuator B Chem. 2018, 266, 246-254. [CrossRef]

23. Zheng, Y.; Cao, X.; Orbulescu, J.; Konka, V.; Andreopoulos, F.M.; Pham, S.M.; Leblanc, R.M. Peptidyl fluorescent chemosensors for the detection of divalent copper. Anal. Chem. 2003, 75, 1706-1712. [CrossRef] [PubMed]

24. Wang, P.; Wu, J.; Di, C.; Zhou, R.; Zhang, H.; Su, P.; Xu, C.; Zhou, P.; Ge, Y.; Liu, D.; et al. A novel peptide-based fluorescence chemosensor for selective imaging of hydrogen sulfide both in living cells and zebrafish. Biosens. Bioelectron. 2017, 92, 602-609. [CrossRef] [PubMed]

25. Wang, P.; Liu, L.; Zhou, P.; Wu, W.; Wu, J.; Liu, W.; Tang, Y. A peptide-based fluorescent chemosensor for multianalyte detection. Biosens. Bioelectron. 2015, 72, 80-86. [CrossRef]

26. Li, Y.; Hong, M.; Lin, Y.; Bin, Q.; Lin, Z.; Cai, Z.; Chen, G. Highly sensitive electrochemical immunoassay for H1N1 influenza virus based on copper-mediated amplification. Chem. Commun. 2012, 48, 6562-6564. [CrossRef] 